Egyptian Journal of Aquatic Biology \& Fisheries

Zoology Department, Faculty of Science,

Ain Shams University, Cairo, Egypt.

ISSN $1110-6131$

Vol. 25(4): 69 - 87 (2021)

www.ejabf.journals.ekb.eg

\title{
Cytochrome P450 1A gene expression in response to therapies for the bacterial
} infection in fish.

\author{
Ahmed M. Hal ${ }^{1}$ and Manal I. El-Barbary ${ }^{2, *}$ \\ ${ }^{1}$ Genetics and Genetic Engineering Lab., National Institute of Oceanography and Fisheries \\ (NIOF), Egypt \\ ${ }^{2}$ Fish Diseases Lab., National Institute of Oceanography and Fisheries (NIOF), Egypt \\ * Correspondence Auther: manal278@yahoo.com
}

ARTICLE INFO

Article History:

Received: Aug. 21, 2021

Accepted: Aug. 30, 2021

Online: Sept. 27, 2021

Keywords:

Cytochrome P450 1A, Aeromonas hydrophila, Pseudomonas

fluorescens, spleen, Oreochromis niloticus

\begin{abstract}
Cytochrome P450 1A (CYP1A), a cytochrome P450 gene, participates in the metabolism of xenobiotics. In this research, levels of CYP1A expression were evaluated in treated and untreated bacterial infections in Oreochromis niloticus organs and histopathological changes in splenic tissues. Twelve groups of $O$. niloticus fish: control $\left(\mathrm{T}_{1-4}\right)$, fish infected with Aeromonas hydrophila $\left(\mathrm{T}_{5^{-}}\right)$, and fish infected with Pseudomonas fluorescens $\left(\mathrm{T}_{9^{-12}}\right)$ groups) were treated with Nigella sativa oil and ciprofloxacin. In the uninfected group, treatment doses did not affect CYP1A expression levels. In infected fish, the level of CYP1A expression significantly increased without treatment while relative CYP1A expression was significantly downregulated when treated with $N$. sativa oil and ciprofloxacin additives. The combined treatments had a synergetic effect on the downregulation of CYP1A expression in the liver and gill. The main histological alterations in the spleen of infected fish were severe hyperplasia of melanomacrophage centers (MMCs), which was higher in the A. hydrophila infected fish than in the $P$. fluorescens infected fish. The results clarify the mechanisms of CYP1A gene expression and MMCs against pathogens and their consequences.
\end{abstract}

\section{INTRODUCTION}

Cytochrome P450 genes (CYPs) produce closely related proteins to metabolize multiple endogenous compounds and xenobiotics. Cytochrome P450 activity takes place in the liver and other organs associated with inflammation and infection (Bezirtzoglou, 2012; Stavropoulou et al., 2018). CYP450 alterations also affect cellular immunity in response to infection (Morgan, 2009). One of the CYPs, the CYP1A gene involved in carcinogen metabolism (Androutsopoulos et al., 2009; Lu et al., 2020), is a valuable indicator of the level of contamination ( Stegeman et al., 2001; Miller et al., 2004; El Barbary, 2018), a stressed condition (Sharifian et al., 2020), and bacterial infections in O. niloticus organs (Hal and El-Barbary, 2020). 
Most fish diseases with notable morbidities, mortalities, and subsequent severe economic losses are bacterial infectious diseases (Olsson et al., 1998). Infections of $A$. hydrophila and $P$. fluorescens are known to be the primary cause of bacterial hemorrhagic septicemia in fish and are widely distributed in aquaculture, especially in a culture system (El-Barbary and Hal, 2016). Multiple procedures have been employed to combat these diseases including sanitary prophylaxis, disinfection, chemotherapy, and antibiotics such as ciprofloxacin which inhibit the action of bacterial topoisomerases, resulting in the rapid death of bacteria (Romero et al., 2012). In addition, the immunostimulants of plant sources have the ability to augment fish immunity in response to infectious diseases by enhancing specific and non-specific immunological defenses (Harikrishnan et al., 2011). Several medicinal herbs have a stimulant and booster effect on the immunity of fishes, such as the extracts of Nigella sativa (Awad et al., 2013). These exhibit useful antimicrobial activity against multi-drug resistant bacteria such as Pseudomonas and Staphylococcus resistant strains (Mashhadian and Rakhshandeh, 2005; Morsi, 2000).

Medicinal plants with an antimicrobial effect have different active components that can possibly alter the activity of cytochrome P450 enzymes (Abd El-Aty et al., 2008). In the case of carbon tetrachloride exposure in rats, $N$. sativa oil offers biological protection through the suppression of CYPs (Ibrahim et al., 2008). The extracts of $N$. sativa interfere with CYP1A in vitro through inhibition of ethoxyresorufin O-deethylation reactions in rats and dogs (Liu et al., 2013). Moreover, an association has been observed between the density of MMCs, which is considered an immune function indicator, and CYP450 expression (Passantino et al., 2014; van der Weiden et al., 1994). Increased density of MMCs has been found in fish whose livers have marked CYP1A expression (Basilone $\boldsymbol{e t}$ al., 2018). Tian $\boldsymbol{e t}$ al. (2020) identified CYP1A1 as an important regulator of macrophage phagocytic activity in bacterial infection. Although the role of cytochrome P450s in infectious and inflammatory states has been widely studied, the behavior and mechanism of CYP1A contributions to immunological responses still needs to be understood and requires further investigation.

This study therefore assesses the levels of CYP1A expression in O. niloticus organs and a histopathological examination of splenic tissue damage after bacterial infection with $N$. sativa oil and/or ciprofloxacin treatment-based diets. The potential changes in the levels of CYP1A expression in the treatment of fish bacterial infection may illuminate the role of CYP1A in the immunological response against fish pathogens.

\section{MATERIALS AND METHODS}

\section{Experimental design}

Experimental healthy $O$. niloticus fish were obtained from El-Serw fish farm, National Institute of Oceanography and Fisheries, and uniformly assigned to 12 groups $\left(\mathrm{T}_{1}-\mathrm{T}_{12}\right.$, Table 1$)$. Two duplicate aquaria were dedicated to each group to produce 
biological replicates acclimated to aquaria that were fed a control diet for two weeks. Each aquarium (40 liters) contained eight fish $(50 \pm 2 \mathrm{~g})$ and was supplied with dechloride freshwater with continuous aeration. The bacterial load injected in a single dose in each fish contained $1 \times 10^{5} \mathrm{CFU}$ resuspended in $100 \mu 1$ sterile phosphate-buffered saline (PBS) for A. hydrophila, acc. no. LC208789 (El-Barbary, 2017) and P. fluorescens, acc. no. LC208785 (El-Barbary \& Hal, 2017). Fish were anesthetized in clove oil solution before the operation (Hamackova et al., 2006). Four groups $\left(T_{1}-T_{4}\right)$ were control groups that were injected intraperitoneally (IP) with the same volume of $100 \mu \mathrm{PBS}$ while the other eight groups were injected IP with A. hydrophila $\left(\mathrm{T}_{5}-\mathrm{T}_{8}\right)$ and $P$. fluorescens $\left(\mathrm{T}_{9}\right.$ $\mathrm{T}_{12}$ ). Fish were fed on four tested diets comprising $30 \%$ protein twice daily at a feeding rate of $3 \%$ of body weight. The tested diets were: (1) a basal diet (BD) without supplemented additives for groups $\mathrm{T}_{1}, \mathrm{~T}_{5}$, and $\mathrm{T}_{9}$; (2) BD supplemented with Nigella sativa oil $7 \%$ for groups $\mathrm{T}_{2}, \mathrm{~T}_{6}$, and $\mathrm{T}_{10}$; (3) BD supplemented with ciprofloxacin 200 $\mathrm{mg} / \mathrm{kg}$ for groups $\mathrm{T}_{3}, \mathrm{~T}_{7}$, and $\mathrm{T}_{11}$; and (4) BD supplemented with a combination of $N$. sativa oil and ciprofloxacin at the same dose for groups $\mathrm{T}_{4}, \mathrm{~T}_{8}$, and $\mathrm{T}_{12}$. The experiment was carried out for 14 days.

Table 1. Experimental design.

\begin{tabular}{|c|c|c|}
\hline Group & Injection & Diet \\
\hline $\mathrm{T}_{1}$ & Saline & Basal Diet \\
\hline $\mathrm{T}_{2}$ & Saline & Basal Diet + Nigella sativa oil $70 \mathrm{ml} / \mathrm{kg}$ \\
\hline $\mathrm{T}_{3}$ & Saline & Basal Diet + ciprofloxacin 200 mg/kg \\
\hline $\mathrm{T}_{4}$ & Saline & Basal Diet + ciprofloxacin with Nigella sativa oil \\
\hline $\mathrm{T}_{5}$ & A. hydrophila & Basal Diet \\
\hline $\mathrm{T}_{6}$ & A. hydrophila & Basal Diet + Nigella sativa oil \\
\hline $\mathrm{T}_{7}$ & A. hydrophila & Basal Diet + ciprofloxacin \\
\hline $\mathrm{T}_{8}$ & A. hydrophila & Basal Diet + ciprofloxacin with Nigella sativa oil \\
\hline $\mathrm{T}_{9}$ & P. fluorescens & Basal Diet \\
\hline $\mathrm{T}_{10}$ & P. fluorescens & Basal Diet + Nigella sativa oil \\
\hline $\mathrm{T}_{11}$ & P. fluorescens & Basal Diet + ciprofloxacin \\
\hline $\mathrm{T}_{12}$ & P. fluorescens & Basal Diet + ciprofloxacin with Nigella sativa oil \\
\hline
\end{tabular}

\section{Histological examination}

Three fish from each group were collected 14 days after the bacterial challenge; three spleens from each group were then sampled. These samples were fixed in $10 \%$ formalin, and the histological examination was performed in accordance with Roberts (2012). Using hematoxylin-eosin (HE), samples were stained and photographed using an ICC50 HD camera and a Leica LAS EZ microscope.

\section{CYP1A gene expression analysis}


The total RNA of $O$. niloticus organs (liver, kidney, gill, muscle, brain, and pituitary) was extracted using a total RNA purification kit (Jena Bioscience). Complementary DNA was synthesized using M-MuLV Reverse transcriptase (SibEnzyme Ltd.) to build the first strand of cDNA with an oligo-dT ${ }_{12-18}$ primer (Bio Basic Inc.) in accordance with the manufacturer's instructions. To analyze the relative expression of CYP1A, the primer for the CYP1A gene (FGCAAATGGCTGCTGCTTGTCA and R-GTGTATCAAGGGTTCATGCCCT) and $\beta$ actin gene as an internal control (F-TCAGGGTGTGATGGTGGGTATG and RCTCAGCTCGTTGTAGAAGGTGT) were used for real-time PCR amplification. Realtime PCR reactions took place in a total volume of $20 \mu$ l containing $4 \mu \mathrm{l}$ HOT FIREPol EvaGreen qPCR Mix Plus (5X), $2 \mu \mathrm{l}$ cDNA (200 ng/ $\mu \mathrm{l}), 0.5 \mu 1$ each for forward/reverse primers, and $13 \mu \mathrm{l} \mathrm{H}_{2} \mathrm{O}$ PCR grade. Real-time PCR was performed at $95{ }^{\circ} \mathrm{C}$ for $10 \mathrm{~min}$, followed by 40 cycles at $95{ }^{\circ} \mathrm{C}$ for $15 \mathrm{~s}$, and annealing at $62^{\circ} \mathrm{C}$ for $15 \mathrm{~s}$ and $72^{\circ} \mathrm{C}$ for $12 \mathrm{~s}$. Melting curves were obtained in a Stratagene MX3005P (ABI, CA, USA) from $65^{\circ} \mathrm{C}$ to $95^{\circ} \mathrm{C}$. The relative CYP1A expression was calculated using the $2-^{\Delta \Delta \mathrm{CT}}$ method (Livak and Schmittgen, 2001) normalized to $\beta$-actin. The expression of CYP1A was represented as the average \pm standard error (in triplicate) of the sample replicates.

\section{Statistical analysis:}

Using IBM SPSS (Version 19), multiple comparisons of gene expression in fish organs were performed with one-way ANOVA followed by Duncan's test.

\section{RESULTS}

\section{Clinical examination of infected fish}

Several A. hydrophila and P. fluorescens infected O. niloticus samples exhibited signs of septicemia such as multiple skin ulcers, scale detachment, hemorrhage, cloudiness of eyes, diffuse abdominal distention, and anal inflammatory changes. Samples of $P$. fluorescens infected fish were characterized by congestion and enlargement of internal organs such as the kidney, spleen, and liver.

\section{Histopathological examination}

In Plates $1 \& 2$, no histopathological changes were detected in control group spleens $\left(\mathrm{T}_{1}\right)$ (Plate 1a,b) or nearly detected in groups fed on supplemented diets that presented a normal formation of red and white pulps $\left(\mathrm{T}_{2}-\mathrm{T}_{4}\right)$. In A. hydrophila infected group $\mathrm{T}_{5}$, the splenic tissue exhibited intense hyperplasia of melanomacrophage centers, infiltration of fibroblasts and necrosis, (Plate 1c). Splenic tissues in infected group such as $\mathrm{T}_{9}$ displayed necrosis (Plate 2a), hemolytic areas in between red pulps with vacuoles and hemosiderin deposits (Plate 2b). The spleen of $A$. hydrophila infected fish groups fed on tested supplemented additives, $N$. sativa oil, ciprofloxacin, and a combination of them ( $\mathrm{T}_{6}, \mathrm{~T}_{7}, \& \mathrm{~T}_{8}$, respectively) exhibited hemorrhage between splenic pulps and inflammatory cells, accumulations of MMCs, and necrosis $\left(\mathrm{T}_{6}\right.$, Plate $\left.1 \mathrm{~d}\right)$. The spleen in 
group $\mathrm{T}_{7}$ displayed severe vacuolation and degeneration of splenic cells, severe hemolysis between pulps, and accumulations of hemosiderin (Plate 1e). In addition to severe accumulations of MMCs and infiltration of fibroblasts found in group $\mathrm{T}_{8}$ (Plate 1f), splenic tissues in $P$. fluorescens infected group $\mathrm{T}_{9}$ exhibited necrosis (Plate 2a) hemolytic areas between red pulps with vacuoles, hemosiderin deposits, and disrupted blood vessels surrounded by fibroblast infiltrates (Plate 2b). These histological alterations in the spleen of $P$. fluorescens infected fish were similar to those observed in treated groups $\mathrm{T}_{10}-\mathrm{T}_{12}$ which fed on the $N$. sativa oil, ciprofloxacin, and a combination of the two, respectively; the spleen in $\mathrm{T}_{10}$ exhibited severe accumulation of MMCs and inflammatory cells (Plate 2c) and severe vacuolation with the deposition of hemosiderin (Plate 2d). The spleen in group $\mathrm{T}_{11}$ exhibited necrosis and severe accumulation of MMCs (Plate 2e) while the spleen in $\mathrm{T}_{12}$ displayed infiltration of erythrocytes and inflammatory cells, hemolysis between splenic pulps, and deposition of hemosiderin (Plate 2f). In general, the histological alterations reduced due to the use of supplemented additives.

\section{CYP1A expression of $O$. niloticus organs}

In uninfected fish group $\mathrm{T}_{1-4}$, treatment with therapeutic additives did not cause any significant alteration in CYP1A expression levels compared to the control $\left(\mathrm{T}_{1}\right)$ in the organs studied. In infected untreated fish $\mathrm{T}_{5} \& \mathrm{~T}_{9}$, the relative expression of CYP1A significantly increased in all organs studied except the pituitary, where the expression was significantly downregulated $\left(T_{5} \& T_{9}\right)$, while the expression in the brain was not affected in the $P$. fluorescens infected fish $\left(\mathrm{T}_{9}\right)$ compared to the control $\left(\mathrm{T}_{1}\right)$. After $A$. hydrophila infection $\left(\mathrm{T}_{5-8}\right), N$. sativa oil led to a significant downregulation of CYP1A gene expression in the liver from 13.5 to 8.4 fold, the kidney from 8 to 4.6 fold, the gill from 6.2 to 4.3 fold, the muscle from 1.5 to 0.8 fold, and the brain from 1.7 to 1.4 fold, and increased CYP1A expression in the pituitary from 0.8 to 1.4 fold ( $\mathrm{p}<0.05$; Fig. 1). Additionally, ciprofloxacin significantly decreased CYP1A expression levels after $A$. hydrophila infection in all studied organs of $O$. niloticus. After $P$. fluorescens infection $\left(\mathrm{T}_{9-12}\right), N$. sativa oil decreased CYP1A expression levels in the liver from 18.6 to 5.3 fold, the kidney from 7.4 to 5.8 fold, the gill from 4.7 to 2.3 fold, and the muscle from 1.5 to 0.8 fold, and resulted in a non-significant increase in the level of CYP1A expression in the brain $\left(\mathrm{T}_{10}\right)$. The relative expression of CYP1A decreased with ciprofloxacin treatment from 18.6 to 6.1 fold in the liver, 7.4 to 6.3 fold in the kidney, 4.7 to 3.2 fold in the gill, and 1.5 to 0.6 fold in the muscle. The combined therapeutic additives ( $N$. sativa oil and ciprofloxacin) significantly decreased levels of CYP1A expression in the liver, kidney, gill and muscle $\left(\mathrm{T}_{8} \& \mathrm{~T}_{12}\right)$ compared to the infected untreated fish $\left(\mathrm{T}_{5} \& \mathrm{~T}_{9}\right)$, but significantly increased in the pituitary in both infection types (Fig. 1). 

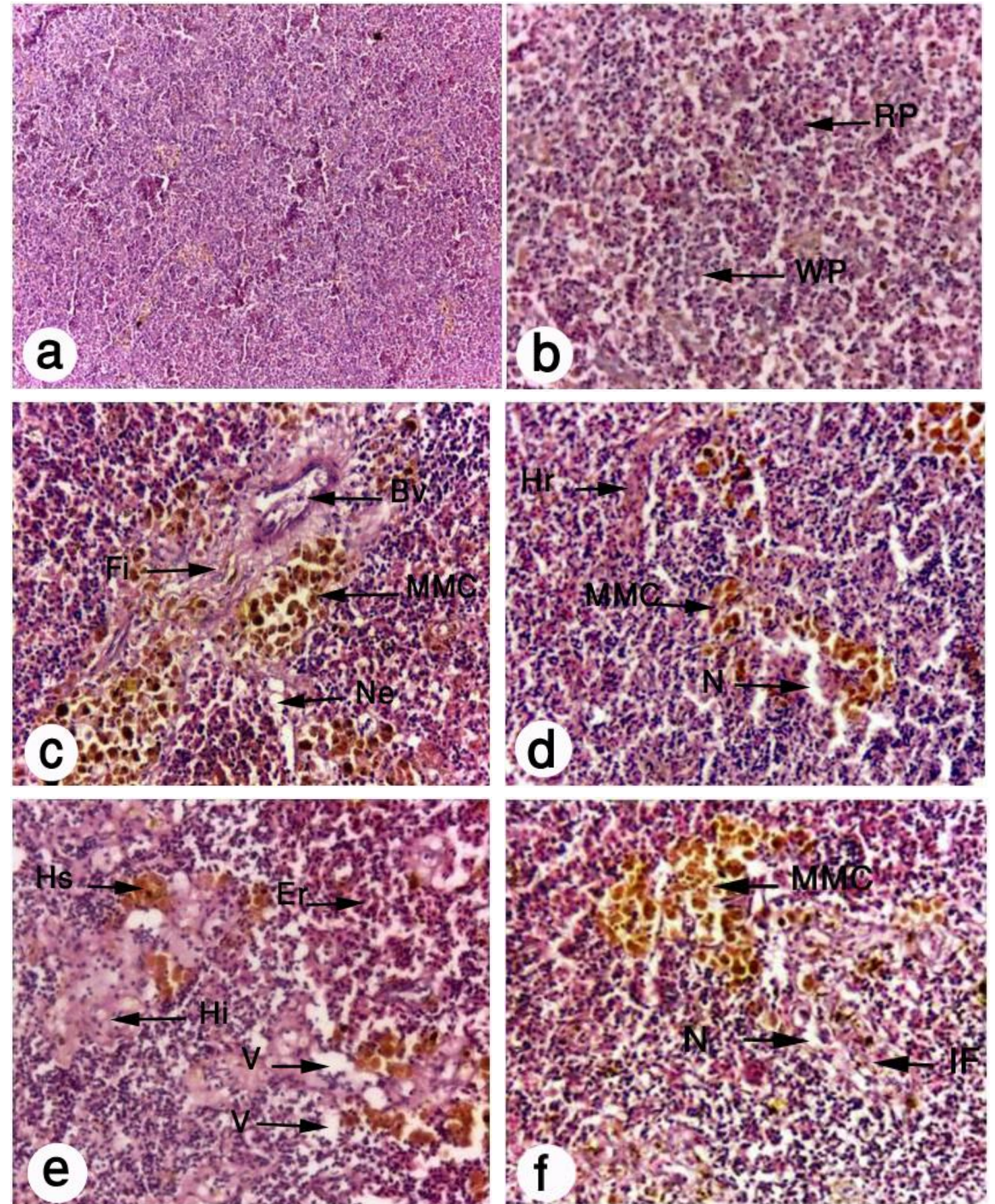

Plate 1 Histopathological changes in the spleen of control group and A. hydrophila infected $O$ niloticus $\left(\mathrm{T}_{1}-\mathrm{T}_{8}\right)$ stained with $\mathrm{H} \& \mathrm{E}$.; $(\mathrm{a}, \mathrm{b}) \mathrm{T}_{1}$ showed normal structure of red and white pulps in spleen $(\mathrm{x} 100,200)$. (c) $\mathrm{T}_{5}$ showed infiltration of fibroblasts between splenic pulps, severe accumulation of MMC around damage blood vessels and necrosis (x200). $\mathrm{T}_{6}$ showed hemorrhage, inflammatory cells and accumulations of MMC with necrosis ( $\mathrm{d} \times 200)$. $\mathrm{T}_{7}$ exhibited vacuolation and degeneration of splenic cells, severe hemolytic between pulps and accumulations of hemosiderin ( $\mathrm{e} \times 200) . \mathrm{T}_{8}$ exhibited severe accumulations of MMC and infiltration of fibroblasts (f $\mathrm{x} 200$ ). $\mathrm{WP}=$ white pulp, $\mathrm{RP}=$ red pulp, $\mathrm{MMC}=$ melanomacrophage cells, $\mathrm{Fi}=$ fibroblasts, $\mathrm{Bv}=$ blood vessel, $\mathrm{He}=$ hemorrhage, $\mathrm{N}=$ necrosis, $\mathrm{Hi}=$ hemolysis, $\mathrm{Hs}=$ hemosiderin . 

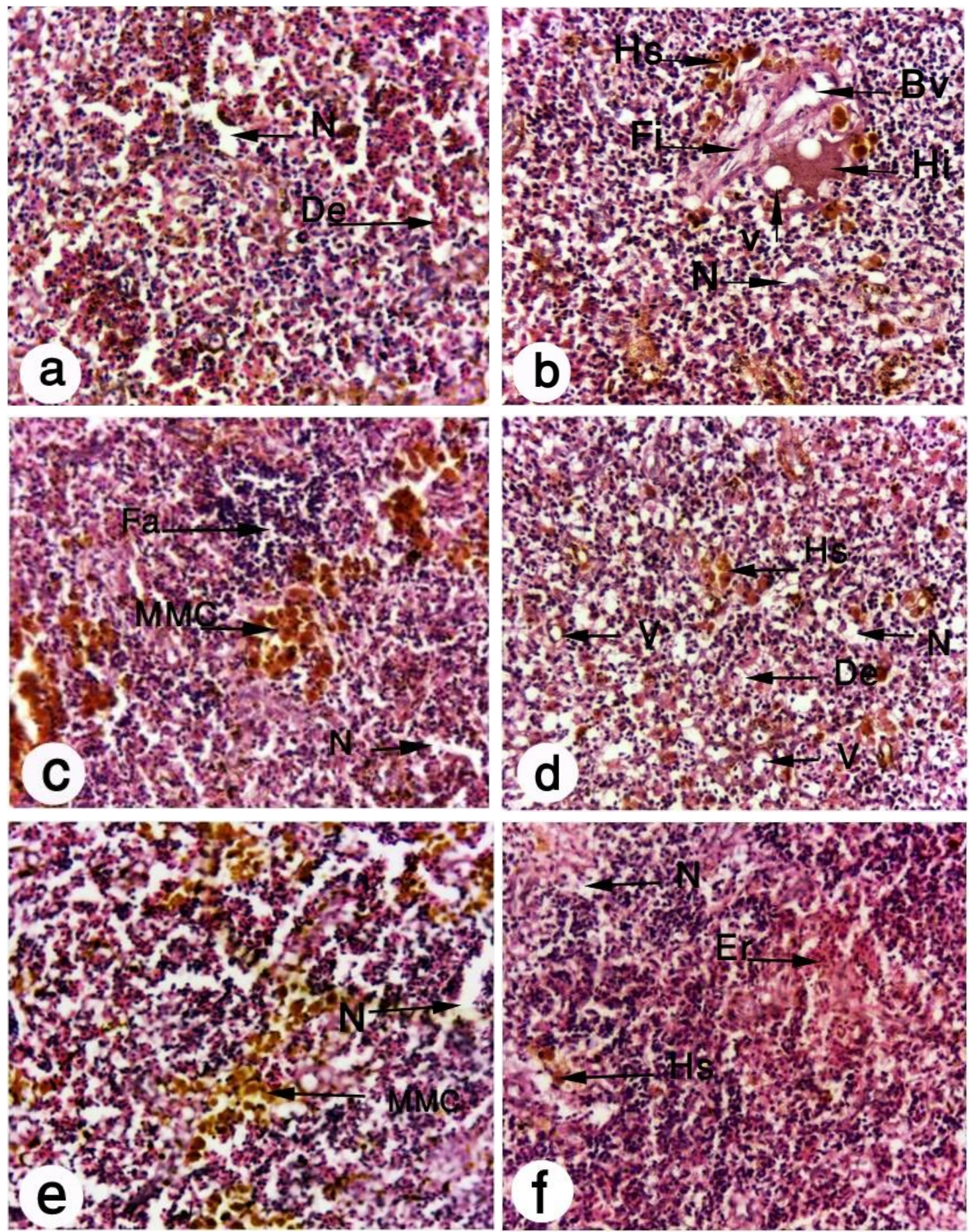

Plate 2 Histopathological changes in the spleen of $P$. fluorscens infected $O$ niloticus $\left(\mathrm{T}_{9}-\mathrm{T}_{12}\right)$ stained with H\&E.; (a, b) $\mathrm{T}_{9}$ showed necrosis (a x200) and infiltration of fibroblasts around damage blood vessels, hemolytic and vacuolation with deposition of hemosiderin (b x200). (c, d) $\mathrm{T}_{10}$ exhibited severe accumulation of (MMCs) and inflammatory cells (c x200) severe vacuolation with deposition of hemosiderin ( $\mathrm{dx} 200) \mathrm{T}_{11}$ showed necrosis and severe accumulation of (MMCs) (e $\mathrm{x} 200) . \mathrm{T}_{12}$ showed infiltration of inflammatory cells and erythrocytes, hemolytic between red pulps and deposition of hemosiderin $(\mathrm{fx} 200)$. $\mathrm{WP}=$ white pulp, $\mathrm{RP}=$ red pulp, $\mathrm{MMC}=$ melanomacrophage cells, $\mathrm{Fi}=$ fibroblasts, $\mathrm{Bv}=$ blood vessel, $\mathrm{He}=$ hemorrhage, $\mathrm{N}=$ necrosis, $\mathrm{Hi}=$ hemolysis, Hs= hemosiderin. Er= erythrocytes. 
Liver

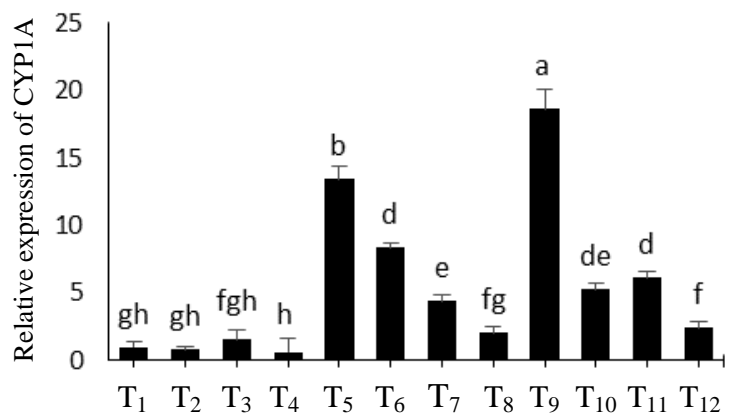

Gill

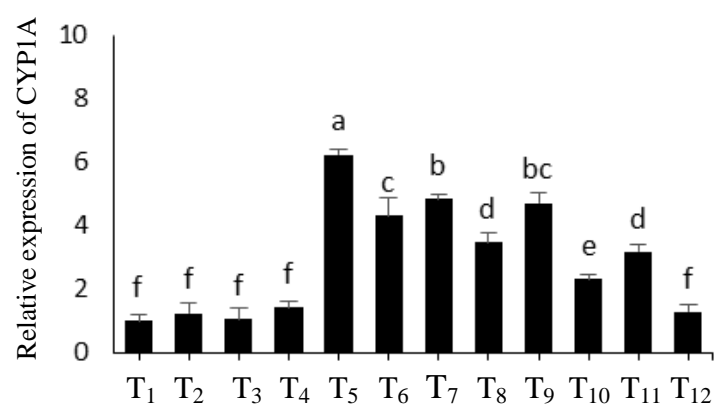

Brain

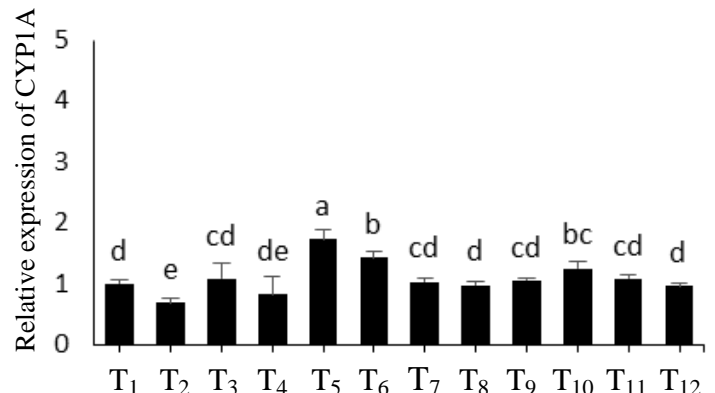

Kidney

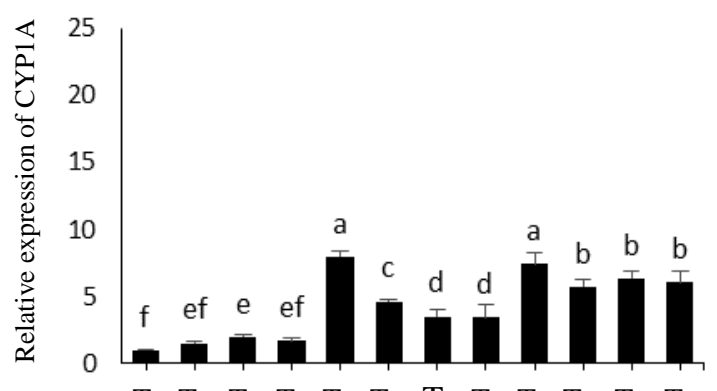

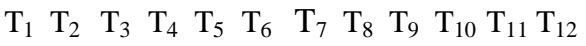

Muscle

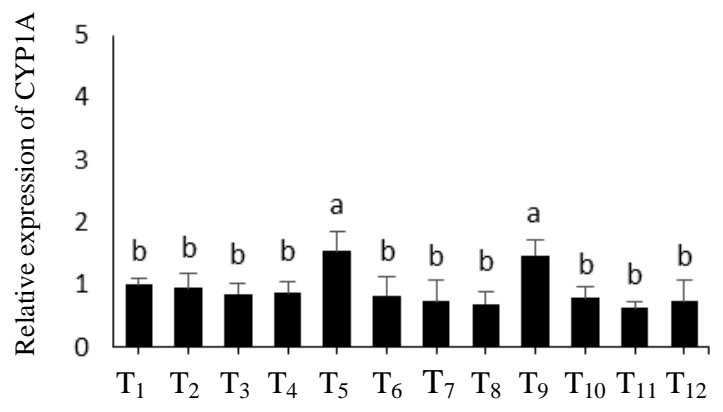

Pituitary

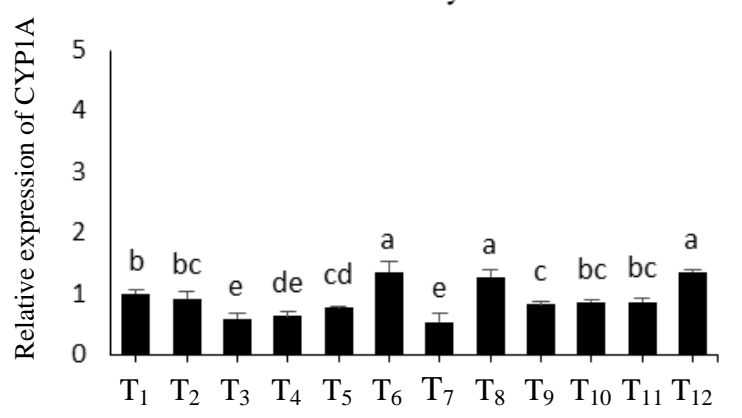

Figure 1. The relative expression of CYP1A of $O$. niloticus studied organs in untreated uninfected fish $\left(\mathrm{T}_{1}\right)$, treated uninfected fish $\left(\mathrm{T}_{2-4}\right)$, with $N$. sativa oil $\left(\mathrm{T}_{2}, \mathrm{~T}_{6}\right.$ and $\left.\mathrm{T}_{10}\right)$, ciprofloxacin $\left(\mathrm{T}_{3}, \mathrm{~T}_{7}\right.$ and $\left.\mathrm{T}_{11}\right)$, and the combination of both $\left(\mathrm{T}_{4}, \mathrm{~T}_{8}\right.$ and $\left.\mathrm{T}_{12}\right)$ after infection with $A$. hydrophila $\left(\mathrm{T}_{5^{-8}}\right)$ and $P$. fluorescens $\left(\mathrm{T}_{9^{-12}}\right)$. Above each column, different letters indicate a significant difference $(\mathrm{P}<0.05)$.

\section{DISCUSSION}

The clinical symptoms in this experimental infection were cloudiness of eyes, scale detachment, ulcers on the skin, hemorrhage, inflammation of the anus, and abdominal distention in some $O$. niloticus. The A. hydrophila and $P$. fluorescens infected fish were characterized by congestion and enlargement of the liver, spleen, and kidney. Some of these signs are consistent with those observed by El-Barbary (2010a, 2010b) and Yambot and Inglis (1994) whose reported that A. hydrophila infection resulted in 
acute mortality and obvious signs such as cloudiness in one or both eyes, which is associated with exophthalmia. Additionally, Hardi and Pebrianto (2012) reported that the Aeromonas infection caused the fish to bleed on the surface of infected organs such as the body, skin, and operculum, while the clinical signs of Pseudomonas sp. are mostly indicated by pale and watery internal organs, and gall bladder ruptures. In infected $O$. niloticus, each Pseudomonas species and A. hydrophila produce toxins and enzymes, such as protease, hemolysins, enterotoxins, cytotoxins, and others which are responsible for their pathogenicity and virulence (Abou El-Geit et al., 2013; Eissa et al., 2010; ElBarbary, 2010a, 2017; El-Barbary and Hal, 2017).

Histopathological examination is a well-established tool utilized to assess the structure and magnitude of tissue changes caused by biological and chemical insults and represents a fair biological marker (Camargo and Martinez, 2007). The spleen has two major components: a lymphopoietic portion (white pulp): a hematopoietic part (red pulp) that make an obvious immunological contribution in fish (Fournier-Betz et al., 2000; Kurtović et al., 2008; Lin et al., 2005), where it is the only lymph-node in bony fish (Roberts, 2012).

In the spleen, notable hypertrophy and hyperplasia of MMCs occurs in response to bacterial infection (Alagappan et al., 2009; Soto et al., 2009). In the present study, the spleen of $O$. niloticus infected with A. hydrophila and $P$. fluorescens exhibited severe hyperplasia of MMCs, infiltration of fibroblasts, and necrosis. In Plates 1, 2, the spleen of infected $O$. niloticus exhibited deposition of MMCs and hemosiderin that was also reported by Chang \& Plumb (1996) and Miyazaki and Kaige (1986) who observed diffuse hemosiderin deposition in the spleen of carps infected by A. hydrophila. MMCs may therefore contribute to humoral adaptive immunity as they are the evolutionary precursors of the mammalian germinal centers (Steinel and Bolnick, 2017) and appeared dark brown with areas patchy of hemopoietic portion depletion (Mahmoud et al., 2018). In addition, histological changes in the spleen identified severe hyperplasia of MMCs in both $A$. hydrophila and $P$. fluorescens infected fish ( $\mathrm{T}_{5} \& \mathrm{~T}_{9}$ respectively). These findings may be attributable to the production by $P$. fluorescens of extracellular proteases, which have a deleterious effect on endothelium and parenchyma that results in pathological hemorrhages and degenerations (Miyazaki et al., 1984). Furthermore, various extracellular toxins and enzymes linked to A. hydrophila and added to other environmental toxicants may be responsible for these lesions (Garcia-Abiado et al., 2004; Gogal et al., 1999). Hemolysis in the infected groups (Plates 1e \& 2f) may be due to damage to erythrocytes membranes (Hibiya, 1982; Scott and Rogers, 1981; Zapata and Cooper, 1990) where abnormal movement and aggregation of intra-splenic erythrocytes is an aspect of splenic congestion and a cause of hemolysis.

In general, the histological alterations were reduced when supplemented additives were used. $N$. sativa is reported to have antibacterial actions against a wide range of microorganisms (Sokmen et al., 1999; Soliman et al., 2017) as well as anti-in- 
flammatory action (Mutabagani \& El-Mahdy, 1997), renal-protective (El Daly, 1998), hepatoprotective (Daba \& Abdel-Rahman, 1998), and immune-potentiating properties (Swamy and Tan, 2000). Similarly, Kaleeswaran et al. (2012) observed that aggregations of splenic MMCs were more evident in experimental groups of Catla catla that fed on the medicinal plants Cynodon dactylon than in the control group, which explains the subsequent inhibition of A. hydrophila growth. Mahmoud et al. (2014) also reported increased MMCs activity in fish spleen treated with spirulina which appears to strongly enhance immunity. Additionally, $N$. sativa oil enhanced the immune response and protection of A. testudineus against A. hydrophila (Khatun et al., 2015) and its action as a disease controlling agent for $C$. carpio against $P$. fluorescens (Khondoker $\boldsymbol{e t}$ al., 2016).

In this study, the increased density of MMCs went along with CYP1A overexpression. Our findings align with previous reports of an association between MMCs and CYP1A in stress conditions and apoptosis (Corriero et al., 2013; Passantino et al., 2014; van der Weiden et al., 1994).

Activities of cytochrome P450s were affected by infection and inflammation with an observed interplay with inflammatory mediators. Several studies have reported a relationship between pollutant-related genes and immunity defense (Brown et al., 2006; Hal \& El-Barbary, 2021a,2021b; Wang et al., 2009). In this study, the relative expression of CYP1A increased in all organs of untreated infected fish except for the pituitary in both infection types and the brain in P. fluorescens infection. Although not all previous studies reported upregulation of CYP1 levels due to infection (e.g., Neyrinck $\boldsymbol{e} \boldsymbol{t}$ al., 2009; Renton and Nicholson, 2000; Tindberg et al., 2004), other studies have reported upregulation of CYP1 levels in response to infection and inflammation (Hussain et al., 2014; Lee et al., 2015; Schiering et al., 2017; Tian et al., 2020). Even in response to parasitic diseases, an increase in total CYP450 content has been detected and the CYP1A1 activity upregulated in rat liver, as observed by Montero et al. (2003). Divanovic et al. (2013) reported that the CYP gene is involved in the metabolism of lipid mediators responsible for the initiation and resolution phase of inflammation and noted that CYP1 monooxygenase participates in their biosynthesis and inactivation and modulates their balance in the inflammatory process. Furthermore, there is an association among CYP1A over expression, down regulation of proinflammatory cytokines, and activation of the PPAR- $\gamma$ signal pathway, which exerts anti-inflammatory action in pigs (Fang et al., 2016).

With $N$. sativa oil treatment, there was a decrease in the levels of CYP1A expression in organs. This aligns with the observations of Ibrahim et al. (2008) who reported that $N$. sativa oil offers biological protection with a suppression effect on CYPs in carbon tetrachloride exposure in rats. In addition, $N$. sativa inhibited CYP1A catalytic activity in the liver of canines and murines (Liu et al., 2013) and decreased relative CYP1A expression in the blood of tilapia after the infection (Hal \& El-Barbary, 2021a). 
In our study, ciprofloxacin decreased CYP1A expression levels after the bacterial infection. Similarly, expressed zebra fish CYP1A has been found to be inhibited by ciprofloxacin (Smith et al., 2012), which exhibited a selective suppression of CYP1A2 (Granfors et al., 2004). Our results indicated that the therapeutic effect of additives $(N$. sativa oil and ciprofloxacin) led to down regulation of CYP1A expression with control of the infection, suggesting that the over expression of CYP may exhaust the immune defense and that down regulation has a protective effect in the bacterial infection. This was observed by Schiering et al. (2017) who reported that exaggerated over expression of CYP may result in undesirable inflammatory sequences with depletion of the aryl hydrocarbon receptor (AHR) tissue store. This hampers the AHR-dependent immune response which, in turn, increases mortality in Citrobacter rodentium infection due to functional depletion of AHR.

Alterations of P450 enzyme activities in the brain by infection or inflammation might therefore modify responses in the central nervous system (CNS). Fish CNS are observed to have a blood-brain barrier structurally similar to the mammalian form with the exception of the hypothalamohypophyseal area. This implies selective permission of systemic mediators and drug entrance to the brain (Orellana-Paucar et al., 2013; Tenor et al., 2015), which has an effect on the CNS behavior of cytochrome levels in terms of stress and inflammatory status. In the current study, the alteration of the relative expression of CYP1A in the brain was slightly increased by infection and decreased by treatments in the A. hydrophila infection, while the expression did not significantly change in the $P$. fluorescens infection group. It has been reported that the levels of brain cytochrome P450 are low with difficult detection of various isoenzymes and nonselective LPS stimulation of several cytochrome isoenzymes (Monshouwer et al., 2000). In other studies, CYP1A was downregulated in response to lipopolysaccharide injection in the cerebroventricular compartment (Renton \& Nicholson, 2000) and LPS injection in the brain affected hepatic cytochrome enzymatic activity (Shimamoto et al., 1998).

In our study, CYP1A expression in the pituitary exhibited different behavior, as it decreased in infection without treatment compared to CYP1A expression in other organs. In fish stress and infection, hypothalamic-pituitary-adrenal axis was observed to have an immune regulatory action through feedback mechanisms in a hypothalamic-pituitary axis in response to systemic cortisol, catecholamine, and cytokine levels (Holland et al., 2002; Verburg-van Kemenade et al., 2017), which may cause a negative feedback effect with decreased metabolic activity. Furthermore, fish exhibited a IL-1 receptor in the pituitary and hypothalamus, which is involved in the stress response (Metz et al., 2006; Pijanowski et al., 2015).

\section{CONCLUSION}

The histopathological examination of spleen tissue of $O$. niloticus infected by $A$. hydrophila and $P$. fluorescens showed that all lesions were observed in all infected 
groups. The severe hyperplasia of MMCs, infiltration, and necrosis were higher in the $A$. hydrophila infected fish group than the $P$. fluorescens group. However, these histopathological alterations reduced with the use of $N$. sativa oil and/or ciprofloxacin. Relative CYP1A expression increased in all studied organs of untreated infected fish. The therapeutic additives ( $N$. sativa oil and ciprofloxacin) led to downregulation of CYP1A expression after infection. However, CYP1A expression exhibits different behavior in the pituitary. These results could help illuminate the mechanisms of CYP1A gene expression and MMCs against the pathogens and their consequences.

\section{ACKNOWLEDGEMENTS}

We would like to thank members of the Department of Genetics, Ain Shams University, for using a Stratagene QPCR.

\section{REFERENCES}

Abd El-Aty, A.M.; Sher Shah, S.; Kim, B. M.; Choi, J. H.; Cho, H. J.; Chang, B. J.; Shin, H.C.; Bong Lee, K.; Shimoda, M. and Shim, J.H. (2008). In vitro inhibitory potential of decursin and decursinol angelate on the catalytic activity of cytochrome P-450 1A1/2, 2D15, and 3A12 isoforms in canine hepatic microsomes. Arch Pharm Res., 31(11): 1425-1435.

Abou El-Geit, E.N.; Saad, T.T.; Abdo, M.H. and Mona, S.Z. (2013). Microbial infections among some fishes and crustacean species during blooming phenomenon in Qaroun Lake-Egypt. Life Sci. J., 10 (2): 1217-1224.

Alagappan, K. M. ; Deivasigamani, B. ; Kumaran, S., and Sakthivel, M. (2009). Histopathological alterations in estuarine catfish (Arius maculatus; Thunberg, 1792) due to Aeronomas hydrophila infection. W. J. Fish and Marine Sciences, 1(3): $185-189$.

Androutsopoulos, V.P.; Tsatsakis, A.M. and Spandidos, D.A. (2009). Cytochrome P450 CYP1A1: Wider roles in cancer progression and prevention. BMC Cancer, 9: 1-17.

Awad, E.; Austin, D. and Lyndon, A.R. (2013). Effect of black cumin seed oil (Nigella sativa) and nettle extract (Quercetin) on enhancement of immunity in rainbow trout, Oncorhynchus mykiss (Walbaum). Aquaculture, 388-391: 193-197.

Basilone, G.; Gargano, A.; Corriero, A.; Zupa, R.; Santamaria, N.; Mangano, S.; Ferreri, R.; Pulizzi, M.; Mazzola, S.; Bonanno, A.and Passantino, L. (2018). Liver melanomacrophage centres and CYP1A expression as response biomarkers to environmental pollution in European anchovy (Engraulis encrasicolus) from the western Mediterranean Sea. Mar. Pollut. Bull., 131: 197-204.

Bezirtzoglou, E.E.V. (2012). Intestinal cytochromes P450 regulating the intestinal microbiota and its probiotic profile. Microb. ecol. health dis., 23(0): 18370.

Brown, M.; Davies, I.M.; Moffat, C.F. and Craft, J.A. (2006). Application of SSH and a 
macroarray to investigate altered gene expression in Mytilus edulis in response to exposure to benzo[a]pyrene. Mar. Environ. Res., 62 (SUPPL. 1): 128-135.

Camargo, M. M. P. and Martinez, C. B. R. (2007). Histopathology of gills, kidney and liver of a Neotropical fish caged in an urban stream. Neotrop Ichthyol., 5(3): 327336.

Chang, P. H. and Plumb, J. A. (1996). Histopathology of experimental Streptococcus sp. infection in tilapia, Oreochromis niloticus (L.), and channel catfish, Ictafurus punctatus (Ratinesque). J. Fish Dis., 19(3): 235-241.

Corriero, A.; Zupa, R.; Pousis, C.; Santamaria, N.; Bello, G.; Jirillo, E.; Carrassi, M.; De Giorgi, C. and Passantino, L. (2013). Increased liver apoptosis and tumor necrosis factor expression in Atlantic bluefin tuna (Thunnus thynnus) reared in the northern Adriatic Sea. Mar. Pollut. Bull., 71(1-2): 23-28.

Daba, M. H., and Abdel-Rahman, M. S. (1998). Hepatoprotective activity of thymoquinone in isolated rat hepatocytes. Toxicol. Lett., 95(1), 23-29.

Divanovic, S.; Dalli, J.; Jorge-Nebert, L.F.; Flick, L.M.; Gálvez-Peralta, M.; Boespflug, N.D.; Stankiewicz, T.E.; Fitzgerald, J.M.; Somarathna, M.; Karp, C. L.; Serhan, C.N. and Nebert, D.W. (2013). Contributions of the three CYP1 monooxygenases to pro-inflammatory and inflammation-resolution lipid mediator pathways. J. Immunol. Res., 191(6): 3347-3357.

Eissa, N.M.; Abou El-Gheit, E.; Shaheen, A. and Abbass, A. (2010). Characterization of Pseudomonas species isolated from Tilapia "O. niloticus" in Qarun and Wadi-ElRayan Lakes, Egypt. Glob. Vet., 5(2): 116-121.

El-Barbary, M.I. (2010a). Some clinical, microbiological and molecular characteristics of Aeromonas hydrophila isolated from various naturally infected fishes. Aquac. Int., 18(5): 943-954.

El-Barbary, M.I. (2010b). Pathogenic characteristics and molecular identification of Aeromonas hydrophila isolated from some naturally infected cultured fishes. Egypt. J. Aquat. Res., 36(2): 345-356.

El-Barbary, M.I. (2017). Serum biochemical and histopathological changes associated with Aeromonas hydrophila isolated from Oreochromis niloticus and Sparus aurata with multiple antibiotic resistance index. Res. J. Biol. Sci., 17(5): 222-234.

El-Barbary, M.I. and Hal, A.M. (2016). Isolation and molecular characterization of some bacterial pathogens in El-Serw fish farm, Egypt. Egypt. J. Aquat. Biol. Fish., 20: $115-127$.

El-Barbary, M.I. and Hal, A.M. (2017). Phenotypic and genotypic characterization of some Pseudomonas sp. Associated with Burkholderia cepacia isolated from various infected fishes. J. Aquac. Res. Dev., 08(07): 499.

El-Barbary, M. I. (2018) Impact of Garlic and Curcumin on the hepatic histology and Cytochrome P450 gene expression of aflatoxicosis Oreochromis niloticus using RTPCR, Turkish J. Fish. Aquat. Sci., 18(3):405-415 
El Daly, E. S. (1998). Protective effect of cysteine and vitamin E, Crocus sativus and Nigella sativa extracts on cisplatin-induced toxicity in rats. J. Pharm. Belg., 53(2): 87-93.

Fang, X.; Zhao, W.; Xu, J.; Tu, F.; Wang, X.; Li, B.; Fu, Y. and Ren, S. (2016). CYP1A1 mediates the suppression of major inflammatory cytokines in pulmonary alveolar macrophage (PAM) cell lines caused by Mycoplasma hyponeumoniae. Dev. Comp. Immunol., 65: 132-138.

Fournier-Betz, V.; Quentel, C.; Lamour, F. and LeVen, A. (2000). Immunocytochemical detection of Ig-positive cells in blood, lymphoid organs and the gut associated lymphoid tissue of the turbot (Scophthalmus maximus). Fish Shellfish Immunol., 10(2): 187-202.

Garcia-Abiado, M. A.; Mbahinzireki, G.; Rinchard, J.; Lee, K. J. and Dabrowski, K. (2004). Effect of diets containing gossypol on blood parameters and spleen structure in tilapia, Oreochromis sp., reared in a recirculating system. J. Fish Dis., 27(6): 359368.

Gogal, J. R. M.; Smith, B. J.; Robertson, J. L.; Smith, S. A. and Holladay, S. D. (1999). Tilapia (Oreochromis niloticus) dosed with azathioprine display immune effects similar to those seen in mammals, including apoptosis. Vet. Immunol. Immunopathol., 68(2-4): 209-227.

Granfors, M.T.; Backman, J.T.; Laitila, J. and Neuvonen, P.J. (2004). Tizanidine is mainly metabolized by cytochrome P450 1A2 in vitro. Br. J. Clin. Pharmacol., 57(3): 349-353. https://doi.org/10.1046/j.1365-2125.2003.02028.x

Hal, A.M. and El-Barbary, M.I. (2020). Gene expression and histopathological changes of Nile tilapia (Oreochromis niloticus) infected with Aeromonas hydrophila and Pseudomonas fluorescens. Aquaculture, 526(April): 735392.

Hal, A.M. and El-Barbary, M.I. (2021a). Effect of Nigella sativa oil and ciprofloxacin against bacterial infection on gene expression in Nile tilapia (Oreochromis niloticus) blood. Aquaculture, 532: 736071.

Hal, A.M., and El-Barbary, M.I. (2021b). Therapeutic effect of Nigella sativa oil and ciprofloxacin against bacterial infection based on interleukin $1 \beta$ expression and kidney histopathological alterations in Oreochromis niloticus. Aquac. Res., 52 (6): 2772-2782.

Hamackova, J.; Kouril, J.; Kozak, P. and Stupka, Z. (2006). Clove oil as an anaesthetic for different freshwater fish species. Bulg. J. Agric. Sci., (12): 185-194.

Hardi, E.H. and Pebrianto, C.A. (2012). Isolation and postulat koch test Aeromonas sp. and Pseudomonas sp. in Tilapia (Oreochromis niloticus) in Loa Kulu aquaculture Kutai Kartanegara. J. Ilmu Perikan. Trop., 16(2): 35-39.

Harikrishnan, R.; Balasundaram, C. and Heo, M.-S. (2011). Impact of plant products on innate and adaptive immune system of cultured finfish and shellfish. Aquaculture, 317(1-4): 1-15. https://doi.org/10.1016/j.aquaculture.2011.03.039 
Hibiya, T. (1982). An atlas of fish histology: Normal and pathological features. Kodansha Ltd., Tokyo.

Holland, J.W.; Pottinger, T.G. and Secombes, C.J. (2002). Recombinant interleukin-1 $\beta$ activates the hypothalamic-pituitary-interrenal axis in rainbow trout, Oncorhynchus mykiss. J. Endocrinol., 175(1): 261-267.

Hussain, T.; Al-Attas, O.S.; Al-Daghri, N.M.; Mohammed, A.A.; De Rosas, E.; Ibrahim, S.; Vinodson, B.; Ansari, M.G. and El-Din, K.I.A. (2014). Induction of CYP1A1, CYP1A2, CYP1B1, increased oxidative stress and inflammation in the lung and liver tissues of rats exposed to incense smoke. Mol. Cell. Biochem., 391(1-2): 127136.

Ibrahim, Z.S.; Ishizuka, M.; Soliman, M.; ElBohi, K.; Sobhy, W.; Muzandu, K.; Elkattawy, A.M.; Sakamoto, K.Q. and Fujita, S. (2008). Protection by Nigella sativa against carbon tetrachloride-induced downregulation of hepatic cytochrome P450 isozymes in rats. Jpn. J. Vet. Res., 56(3): 119-128.

Kaleeswaran, B.; Ilavenil, S. and Ravikumar, S. (2012). Changes in biochemical, histological and specific immune parameters in Catla catla (Ham.) by Cynodon dactylon (L.). J. King Saud Univ. Sci., 24(2): 139-152.

Khatun, A.; Hossain, M.M.M.; Rahman, M.Z. and Alam, M.E. (2015). Effect of black cumin seed oil (Nigella sativa) on enhancement of immunity in the climbing perch, Anabas testudineus. Br. Microbiol. Res. J., 6(6): 331-339.

Khondoker, S.; Mer Mosharraf Hossain, M.; Hasan-Uj-Jaman, M.; Eftakher Alam, M.; Farid Uz Zaman, M. and Tabassum, N. (2016). Effect of Nigella sativa (Black Cumin Seed) to enhance the immunity of common carp (Cyprinus carpio) against Pseudomonas fluorescens. Am. J. Life Sci., 4(3): 87-92.

Kurtović, B.; Teskeredžić, E. and Teskeredžić, Z. (2008). Histological comparison of spleen and kidney tissue from farmed and wild European sea bass. Acta Adriat., 49: $147-154$.

Lee, Y.H.; Lin, C.H.; Hsu, P.C.; Sun, Y.Y.; Huang, Y.J.; Zhuo, J.H.; Wang, C.Y.; Gan, Y.L.; Hung, C.C.; Kuan, C.Y. and Shie, F.S. (2015). Aryl hydrocarbon receptor mediates both proinflammatory and anti-inflammatory effects in lipopolysaccharideactivated microglia. GLIA, 63(7): 1138-1154.

Liu, X.; Park, J. H.; Abd El-Aty, A.M.; Assayed, M.E.; Shimoda, M. and Shim, J.H. (2013). Isolation of volatiles from Nigella sativa seeds using microwave-assisted extraction: Effect of whole extracts on canine and murine CYP1A. Biomed. Chromatogr., 27(7): 938-945.

Livak, K.J. and Schmittgen, T.D. (2001). Analysis of relative gene expression data using real-time quantitative PCR and the 2(-Delta Delta C(T)) Method. Methods (San Diego, Calif.), 25(4): 402-408.

Lu, J.; Shang, X.; Zhong, W.; Xu, Y.; Shi, R. and Wang, X. (2020). New insights of CYP1A in endogenous metabolism: a focus on single nucleotide polymorphisms and 
diseases. Acta Pharm. Sin. B., 10: 91-104.

Lin, H.; Lin, H. and Yang, H. (2005). Histology and histochemical enzyme-staining patterns of major immune organs in Epinephelus malabaricus. J. Fish Biol., 66(3): 729-740.

Mahmoud, M.M.A.; El-Lamie, M.M.M.; Dessouki, A.A. and Yusuf, M.S. (2014). Effect of turmeric (Curcuma longa) supplementation on growth performance, feed utilization, and resistance of Nile tilapia (Oreochromis niloticus) to Pseudomonas fluorescens challenge. GJFSA, 1(12): 26-33.

Mahmoud, M.M.A.; El-Lamie, M.M.M.; Kilany, O.E., and Dessouki, A.A. (2018). Spirulina (Arthrospira platensis) supplementation improves growth performance, feed utilization, immune response, and relieves oxidative stress in Nile tilapia (Oreochromis niloticus) challenged with Pseudomonas fluorescens. Fish Shellfish Immunol., 72: 291-300.

Mashhadian, N.V. and Rakhshandeh, H. (2005). Antibacterial and antifungal effects of Nigella sativa extracts against $S$. aureus, P. aeroginosa and C. albicans. Pak. J. Med. Sci., 21(1): 47-52.

Metz, J.R.; Huising, M.O.; Leon, K.; Verburg-van Kemenade, B.M.L. and Flik, G. (2006). Central and peripheral interleukin-1 $\beta$ and interleukin-1 receptor I expression and their role in the acute stress response of common carp, Cyprinus carpio L. J. Endocrinol., 191(1): 25-35.

Miller, K.A.; Addison, R.F. and Bandiera, S.M. (2004). Hepatic CYP1A levels and EROD activity in English sole: Biomonitoring of marine contaminants in Vancouver Harbour. Mar. Environ. Res., 57(1-2): 37-54. https://doi.org/10.1016/S01411136(03)00059-X

Miyazaki, T. and Kaige, N. (1986). A histopathological study on motile aeromonad disease of crucian carp. Fish Pathol., 21(3): 181-185.

Miyazaki, T.; Kubota, S.S. and Miyashita, T. (1984). A histopathological study of Pseudomonas fluorescens infection in tilapia. Fish Pathol., 19(3), 161-166.

Monshouwer, M.; Agnello, D.; Ghezzi, P. and Villa, P. (2000). Decrease in brain cytochrome P450 enzyme activities during infection and inflammation of the central nervous system. Neuroimmunomodulation, 8(3): 142-147.

Montero, R.; Serrano, L.; Dávila, V.M.; Ito, A. and Plancarte, A. (2003). Infection of rats with Taenia taeniformis metacestodes increases hepatic CYP450, induces the activity of CYP1A1, CYP2B1 and $\mathrm{COH}$ isoforms and increases the genotoxicity of the procarcinogens benzo[a]pyrene, cyclophosphamide and aflatoxin B1. Mutagenesis, 18(2): 211-216.

Morgan, E.T. (2009). Impact of infectious and inflammatory disease on cytochrome P450-mediated drug metabolism and pharmacokinetics. Clin. Pharmacol. Ther., 85(4): 434-438. https://doi.org/10.1038/clpt.2008.302 
Morsi, N.M. (2000). Antimicrobial effect of crude extracts of Nigella sativa on multiple antibiotics-resistant bacteria. Acta Microbiol. Pol., 49(1): 63-74.

Mutabagani, A. and El-Mahdy, S. A. (1997). Study of the anti-inflammatory activity of Nigella sativa L and thymoquinone in rats, Saudi Pharm. Saudi Pharm. J., 5(2-3): 110-113.

Neyrinck, A.M.; Cani, P.D.; Dewulf, E. M.; De Backer, F.; Bindels, L.B. and Delzenne, N.M. (2009). Critical role of Kupffer cells in the management of diet-induced diabetes and obesity. Biochem. Biophys. Res. Commun., 385(3): 351-356.

Olsson, J.; Westerdahl, B. and Kjelleberg C. (1998). Survival, persistence and proliferation of Vibrio anguillarum in juvenile turbot, Scophthalmus maximus (L.), intestine and faeces. J. Fish Dis., 21(1): 1-9.

Orellana-Paucar, A.M.; Afrikanova, T.; Thomas, J.; Aibuldinov, Y.K.; Dehaen, W.; de Witte, P.A.M. and Esguerra, C.V. (2013). Insights from zebrafish and mouse models on the activity and safety of ar-turmerone as a potential drug candidate for the treatment of epilepsy. PloS One, 8(12): e81634.

Passantino, L., Santamaria, N., Zupa, R., Pousis, C., Garofalo, R., Cianciotta, A., Jirillo, E., Acone, F. and Corriero, A. (2014). Liver melanomacrophage centres as indicators of Atlantic bluefin tuna, Thunnus thynnus L. well-being. J. Fish Dis., 37(3): 241-250.

Pijanowski, L.; Jurecka, P.; Irnazarow, I.; Kepka, M.; Szwejser, E.; Verburg-Van Kemenade, B.M.L. and Chadzinska, M. (2015). Activity of the hypothalamuspituitary-interrenal axis (HPI axis) and immune response in carp lines with different susceptibility to disease. Fish Physiol. Biochem., 41(5): 1261-1278.

Renton, K.W. and Nicholson, T.E. (2000). Hepatic and central nervous system cytochrome P450 are down-regulated during lipopolysaccharide-evoked localized inflammation in brain. J Pharmacol Exp Ther., 294(2): 524-530. https://pubmed.ncbi.nlm.nih.gov/10900228/

Romero, J.; Gloria, C. and Navarrete, P. (2012). Antibiotics in Aquaculture - Use, Abuse and Alternatives. In Health and Environment in Aquaculture. InTech., pp. 159-198. https://doi.org/10.5772/28157

Roberts, R.J. (2012). Fish Pathology (4th Edition). Wiley-Blackwell, UK.

Schiering, C.; Wincent, E.; Metidji, A.; Iseppon, A.; Li, Y.; Potocnik, A. J.; Omenetti, S.; Henderson, C. J.; Wolf, C. R.; Nebert, D. W. and Stockinger, B. (2017). Feedback control of AHR signalling regulates intestinal immunity. Nature, 542(7640): 242245.

Sharifian, S.; Homaei, A.; Kamrani, E.; Etzerodt, T. and Patel, S. (2020). New insights on the marine cytochrome P450 enzymes and their biotechnological importance. Int. J. Biol. Macromol., 142: 811-821.

Shimamoto, Y.; Kitamura, H.; Hoshi, H.; Kazusaka, A.; Funae, Y.; Imaoka, S.; Saito, M. and Fujita, S. (1998). Differential alterations in levels of hepatic microsomal 
cytochrome P450 isozymes following intracerebroventricular injection of bacterial lipopolysaccharide in rats. Arch. Toxicol., 72(8): 492-498.

Smith, E.M.; Iftikar, F.I.; Higgins, S.; Irshad, A.; Jandoc, R.; Lee, M. and Wilson, J.Y. (2012). In vitro inhibition of cytochrome P450-mediated reactions by gemfibrozil, erythromycin, ciprofloxacin and fluoxetine in fish liver microsomes. Aquat. Toxicol., 109: 259-266.

Scott, A.L. and Rogers, W.A. (1981). Haematological effects of prolonged sublethal hypoxia on channel catfish Ictalurus punctatus (Rafinesque). J. Fish Biol., 18(5): 591-601.

Sokmen, A.; Jones, B.M. and Erturk, M. (1999). Antimicrobial activity of extracts from the cell cultures of some Turkish medicinal plants. Phytother Res ., 13(4): 355-357.

Soliman, E.S.; Hamad, R.T. and Ahmed, A. (2017). Prophylactic and immune modulatory influences of Nigella sativa Linn. in broilers exposed to biological challenge. Vet. World., 10(12): 1447-1455.

Soto, E.; Hawke, J.P.; Fernandez, D. and A Morales, J. (2009). Francisella sp., an emerging pathogen of tilapia, Oreochromis niloticus (L.), in Costa Rica. J. Fish Dis., 32(8): 713-722.

Stavropoulou, E.; Pircalabioru, G.G.; and Bezirtzoglou, E. (2018). The Role of cytochromes P450 in infection. Front. Immunol. 9: 89.

Stegeman, J.J.; Schlezinger, J.J.; Craddock, J.E. and Tillitt, D.E. (2001). Cytochrome P450 1A expression in midwater fishes: Potential effects of chemical contaminants in remote oceanic zones. Environ. Sci. Technol., 35(1): 54-62.

Steinel, N.C. and Bolnick, D.I. (2017). Melanomacrophage centers as a histological indicator of immune function in fish and other poikilotherms. Front. Immunol. , 8: 827.

Swamy, S. M. and Tan, B. K. (2000). Cytotoxic and immunopotentiating effects of ethanolic extract of Nigella sativa L. seeds. J. Ethnopharmacol., 70(1): 1-7.

Tenor, J.L.; Oehlers, S.H.; Yang, J. L.; Tobin, D.M. and Perfect, J.R. (2015). Live imaging of host-parasite interactions in a zebrafish infection model reveals Cryptococcal determinants of virulence and central nervous system invasion. MBio, 6(5): $\mathrm{e} 01425-15$.

Tian, L.-X.; Tang, X.; Zhu, J.-Y.; Luo, L.; Ma, X.-Y.; Cheng, S.-W.; Zhang, W.; Tang, W.-Q.; Ma, W.; Yang, X.; Lv, C.-Z. and Liang, H.-P. (2020). Cytochrome P450 1A1 enhances inflammatory responses and impedes phagocytosis of bacteria in macrophages during sepsis. Cell Commun. Signal., 18(1): 70.

Tindberg, N.; Bengtsson, I. and Hu, Y. (2004). A novel lipopolysaccharide-modulated Jun binding repressor in intron 2 of CYP2E1. J. Neurochem., 89(6): 1336-1346. https://doi.org/10.1111/j.1471-4159.2004.02449.x

van der Weiden, M.E.J.; Bleumink, R.; Seinen, W. and van den Berg, M. (1994). Concurrence of P450 1A induction and toxic effects in the mirror carp (Cyprinus 
carpio), after administration of allow dose of 2,3,7,8-tetrachlorodibenzo-p-dioxin. Aquat. Toxicol., 29(3-4): 147-162.

Verburg-van Kemenade, B.M.L.; Cohen, N. and Chadzinska, M. (2017). Neuroendocrine-immune interaction: Evolutionarily conserved mechanisms that maintain allostasis in an ever-changing environment. Dev. Comp. Immunol., 66: 223.

Wang, Z.; Nishimura, Y.; Shimada, Y.; Umemoto, N.; Hirano, M.; Zang, L.; Oka, T.; Sakamoto, C.; Kuroyanagi, J. and Tanaka, T. (2009). Zebrafish beta-adrenergic receptor mRNA expression and control of pigmentation. Gene, 446(1): 18-27.

Yambot, A.V and Inglis, V. (1994). Aeromonas hydrophila isolated from Nile Tilapia (Oreochromis niloticus L.) with "eye Disease." International Symposium on Aquatic Animal Health, Seattle, WA (USA), 4th-8th September, University of California, School of Veterinary Medicine, Davis, CA: 103pp.

Zapata, A. G. and Cooper, E. L. (1990). The immune system: comparative histophysiology. John Wiley \& Sons: Chichester, 335 pp. 